\title{
HIGH VALUE SCRAP TIRE RECYCLE
}

\author{
'Project Final Report on \\ VISTAMER ${ }^{\circledR}$ Polymer Paints \\ Containing Recycled Scrap Rughber Particles'

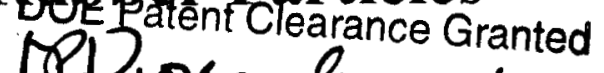 \\ $\frac{\text { MarkP Dvorscak }}{6.3 .05}$ \\ (630) 252-2343 \\ E-mail mark.dvorscak ch.doe.gov \\ DOE Chicago Operations Officew
}

\author{
By: Bernard D. Bauman
}

Composite Particles, Inc.

P.O. Box 218803 Houston, TX 77218-8803

Work Performed Under Cooperative Agreement No. DE-FCO2-93CE41035

For

U.S. Department of Energy

Office of Industrial Technologies 


\section{DISCLAIMER}

This report was prepared as an account of work sponsored by an agency of the United States Government. Neither the United States Government nor any agency Thereof, nor any of their employees, makes any warranty, express or implied, or assumes any legal liability or responsibility for the accuracy, completeness, or usefulness of any information, apparatus, product, or process disclosed, or represents that its use would not infringe privately owned rights. Reference herein to any specific commercial product, process, or service by trade name, trademark, manufacturer, or otherwise does not necessarily constitute or imply its endorsement, recommendation, or favoring by the United States Government or any agency thereof. The views and opinions of authors expressed herein do not necessarily state or reflect those of the United States Government or any agency thereof. 


\section{DISCLAIMER}

Portions of this document may be illegible in electronic image products. Images are produced from the best available original document. 


\section{Acknowledgement of Support:}

This material is based upon work supported by the U.S.

Department of Energy under cooperative Agreement No. DEFCO2-93CE41035

\section{Disclaimer:}

Any opinions, findings, and conclusions or recommendations expressed in this material are those of the author and do not necessarily reflect the views of the Department of Energy. 


\section{CONTENTS}

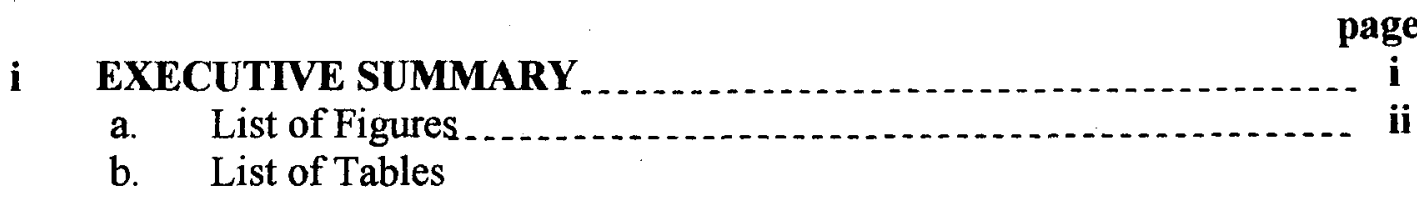

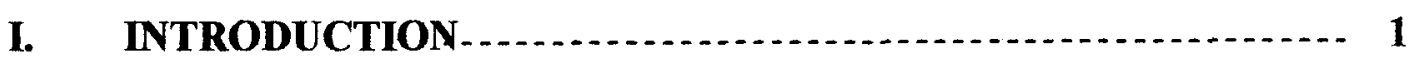
a. Scrap Tires
b. Surface-Modification is Best Technology
c. Background/History
d. Importance of High Vialue
e. Objectives of this Project

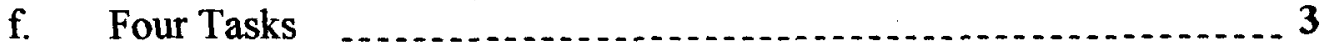

II. RESULTS $\ldots \ldots \ldots \ldots$

a. Task I - Process Development and Scale Up

1. Description of Surface-Modification

2. Formation of New Composites .............................

3. Treatment Process

4. Task I Results

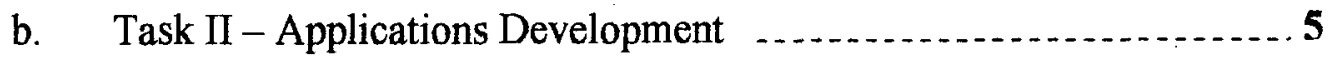

1. Particularly Challenging

2. Task II Results

a. Consultants

b. Presentations, Articles and Technical Literature

c. Demonstrated End-Uses

d. Market Summary . . . $\ldots \ldots$

c. Task III - Economics, Energy, and Environmental Impact .......... 11

1. Economics

2. Prices for Various Types of Polymers

3. Energy

4. Environmentally Friendly and Non-Polluting

d. Task IV - Technology Transfer

III. CONCLUSIONS and RECOMMENDATIONS

\section{APPENDIX}

I. Consultant Reports

II. Technical Bulletins

III. Presentations/papers 


\section{a. List OF Figures}

\section{Page}

Figure $1 \quad$ Patented Reactive Gas Technology 3

Figure 2 Polymer-Polymer Composite Structure

b. LIST OF TABLES

Table 1 Matrix Polymers $\quad 6$

Table 2 Summary of Demonstrated Markets for VISTAMER ${ }^{\text {TM }}$ Rubber 10

Table $3 \quad$ Variable Costs 11

Table 4 Capital Costs 11

$\begin{array}{ll}\text { Table } 5 & \text { Prices for Matrix Polymers }\end{array}$ 


\section{i EXECUTIVE SUMMARY}

The objectives of this project were to further develop and scale-up a novel technology for reuse of scrap tire rubber, to identify and develop end uses for the technology (products), and to characterize the technology's energy savings and environmental impact.

The technology is reactive gas surface-modification of scrap rubber particles. It starts with scrap rubber that has been size reduced (ground) to specific sizes for different applications. The surface-modification process consists of exposing the rubber particles to a reactive gas atmosphere that causes a chemical change in the outer few molecular layers. This permanent chemical reaction functionalizes the surface, i.e., it creates reactive functional groups on the surface that include hydroxyl $(-\mathrm{OH})$ and carboxyl $\left(-\mathrm{CO}_{2} \mathrm{H}\right)$ groups. These new functional groups change the inert rubber particles into additives that are compatible with and able to chemically combine with other polymers. The combination of surface-modified rubber particles with other polymers actually results in formation of novel composite materials which have unique physical properties.

The most important issue addressed by this phase of the project was whether there are substantial markets for surface-modified rubber particles. Answering this question was somewhat complicated. Surface-modified rubber particles are designed to be used in applications where non-treated rubber particles do not work well. When surfacemodified rubber particles are combined with other polymers, all of the resulting material properties are changed. In order for a material to be amenable for a specific application many physical property requirements must be met.

The conclusion concerning amenable market is that there is a huge and diverse potential for this technology. A large number of potential applications were evaluated by Composite Particles, Inc., by consultants subcontracted, and by potential customers in the market place. While an impressive list of demonstrated markets was established, we believe that there are many more applications yet to be developed.

The ultimate market for surface-modified rubber particles in the U.S. is projected to be approximately 1 billion lb/year, with a market value of approximately $\$ 650$ million/year. This estimate is based on our understanding of the fundamental properties that can be imparted by the treated rubber particles, and our understanding of the widespread value of those properties in material engineering.

In this final phase of this project, the technology was shown to be easily scaled up, to be very inexpensive in terms of capital requirements and variable costs, and to have large potential markets in diverse applications and market sectors.

As a result, reactive gas surface-modification of scrap tire rubber has proven to be the best technology for enhancing the value of scrap rubber and for enabling its reuse in the manufacture of other end products. Increasing the value of scrap rubber is important for making recycle economically viable and attractive. The fact that surface-modified rubber can be used in large quantities in numerous applications in many industries is important because this means that this technology can play a significant role in the reutilization of the Nation's scrap tire rubber. Furthermore, this technology offers the greatest energy savings (recovery) of all scrap rubber recycle technologies. 


\section{INTRODUCTION}

\section{A. Scrap Tires}

Scrap tires are a problem - and an opportunity. As a post-consumer waste, tires have relatively few uses in comparison to the numbers discarded each year. Whole tires are known to "float' to the surface over time and disrupt the layered structure of modern landfills. Some unused tires that are not landfilled are collected in tire piles. These frequently catch fire. Tire fires are difficult to extinguish, and they create considerable air, land, and water pollution. Scrap tire piles are ideal breeding grounds for mosquitoes and rats. Outbreaks of encephalitis in the U.S. have been traced to scrap tire piles. Also, the non-reuse of over 7 billion lb/year of scrap tires constitutes a major lost resource.

The rubber used to make automotive tires is a remarkable engineering material with unparalleled performance properties. Its unique combination of strength, toughness, temperature stability, and environmental stability make it a valuable ingredient for the manufacture of numerous other end products. In the past, it was almost impossible to reuse rubber from scrap tires, except for using it as an inert filler. It cannot be "melted down" into new tires because it is a thermoset. Attempts to incorporate ground rubber particles into rubber and plastic materials leads to poor physical properties because of little or no bonding to other materials.

\section{B. Surface-Modification is Best Technology for Scrap Rubber Reuse}

The surface-modification technology developed under this program is the best available technology for reuse of scrap tire rubber. It enables scrap rubber to be used in demanding applications, where it has high value and thus supports recycling costs. Composite Particles, Inc. sold surface-modified rubber particles under the VISTAMER ${ }^{\circledR}$ trademark at pricing ranging from $\$ 0.50 / \mathrm{lb}$ to $\$ 1.49 / \mathrm{lb}$.

It is noteworthy that this is greater than the price for virgin rubber, which ranges from $\$ 0.35$ - $\$ 0.90 / \mathrm{lb}$. This high pricing is supported because VISTAMER ${ }^{\text {TM }}$ rubber is used in applications that virgin rubber generally cannot be used in, and because it gives physical properties and performance that are superior to those obtained through the use of nontreated rubber particles. It is also noteworthy that use of scrap rubber as a fuel is in competition with coal, which is priced at $\$ 0.03-0.04 / \mathrm{lb}$.

In addition to being the highest economic value for scrap rubber, this technology also represents the highest energy value for scrap rubber. The high energy value arises from the fact that surface-modified scrap rubber particles are used in place of virgin polymers in various applications, and because the energy requirement to make surface-modified rubber particles are modest. It is estimated that it takes approximately $30,000-100,000$ BTUs to manufacture a pound of virgin polymer. It only requires approximately 2,000 BTU to make $1 \mathrm{lb}$ of surface-modified rubber particles. Thus the energy saved by using surface-modified rubber particles in place of virgin polymers is approximately 28,000 $98,000 \mathrm{BTU} / \mathrm{lb}$. In comparison, burning scrap tires for energy only recovers about $14,000 \mathrm{BTU} / \mathrm{lb}$. It is projected that the use of this technology can save the nation in excess of 0.4 Quad BTU/year. 


\section{Background/History}

In 1987, the Department of Energy, Office of Industrial Technologies, issued a Request for Proposals to support the development of technologies that will reduce the negative environmental impact and lost energy associated with unused discarded scrap tires.

An innovative technology invented by Air Products and Chemicals, Inc. was selected for support. This technology was partially supported by DOE funding through 1993. At that time, Air Products had decided to not pursue this further because it was not a good fit with the company' core business interests. However, the inventor of the technology was (and still is) a strong believer in the potential for this technology. He acquired rights to the technology from Air Products, and founded a new company for the purpose of continuing the development and commercialization of this technology.

This new company, Composite Particles, Inc., was awarded this cooperative agreement in 1993 for the purpose of further developing and commercializing this technology.

\section{Importance of High-Value}

Scrap tires are highly-engineered automotive components composed of very durable, high performance materials that can be reused in high-value applications. Furthermore, scrap tires are already source separated from other waste materials, and collected in centralized locations. All that is needed is technology for enabling the rubber from scrap tires to be reformed into end products having sufficient physical properties to make its' use economically viable.

The highest value for reusing scrap tires is in applications where the rubber is reused as an engineering material, as opposed to a fuel. Rubber and other elastomeric materials have prices ranging from $\$ 0.50-\$ 5.00 / \mathrm{lb}$. In contrast, scrap tier rubber used as a fuel is competing with coal, which costs approximately $\$ 0.03-0.04 / \mathrm{lb}$.

The reuse of scrap tire rubber has been a challenge in the past. Because the rubber is a crosslinked polymer (thermoset), it cannot be simply melted down and molded into new products. Heating rubber above a critical temperature simply results in decomposition of the rubber. Combining ground-up scrap rubber with uncured rubber or other moldable polymer materials followed by molding/curing has not been particularly successful thus far. This is because of poor bonding between the rubber particles and moldable resins. This results in end products with inferior physical properties. Thus, these end products generally find applications with lower performance requirements. Materials that are used in low-end applications generally are low priced. When rubber is used in such applications, it generally is priced in the range of $\$ 0.10-\$ 0.35 / \mathrm{lb}$. In these applications the rubber is competing with other inexpensive inert fillers, such as sand and calcium carbonate.

\section{E. Objectives of this Project}

The objectives of this project were to further develop and commercialize a new approach to reuse rubber from the nation's scrap tires. Widespread utilization of this technology will reduce the nation's accumulation of scrap tires, will save a considerable amount of energy and raw materials (ultimately oil), and will facilitate the manufacture of end products with superior performance. 


\section{F. Four Tasks}

The project was organized into four tasks:

Task I Process Development and Scale up

Task II Applications Development; developing commercial acceptance by end users

Task III Calculate the Economics, Energy Savings, and Environmental Impact of the technology

Task IV Technology Transfer; Writing technical papers and giving technical presentations in order to promote utilization of the technology.

\section{RESULTS}

The results from performance of this project will be discussed according to the four tasks (above). Some overview discussion will precede some of the results to aid the reader in putting the results in perspective.

\section{A. Task I - Process Development \& Scale Up}

\section{Description of Surface-Modification}

Surface-modification is a unique technology for recycling scrap tire rubber into high value applications. This approach consists of modifying the exterior surface of scrap tire nubber that has been finely ground and liberated from the metal and fabric. The rubber particles are surface-modified in order to facilitate combination with other types of polymers. In comparison to untreated rubber, particles that have been surface-modified are more compatible with and bond more tenaciously to other types of polymers. When surface-modified rubber particles are combined with other continuous phase polymers, novel "composites" are formed. These "composite" materials made with treated rubber particles frequently have physical properties that enable their use in high-performance, high-value applications.

The first surface-modification developed was chlorooxidation. This treatment causes the formation of polar groups such as hydroxyl, carboxylate, and chlorine atoms on the surface, Figure 1. These moieties cause the normally hydrophobic rubber particles to become very hydrophilic; they are readily wetted by water. These polar groups enhance the dispersibility and bonding of rubber particles in other polymer materials.

Figure 1

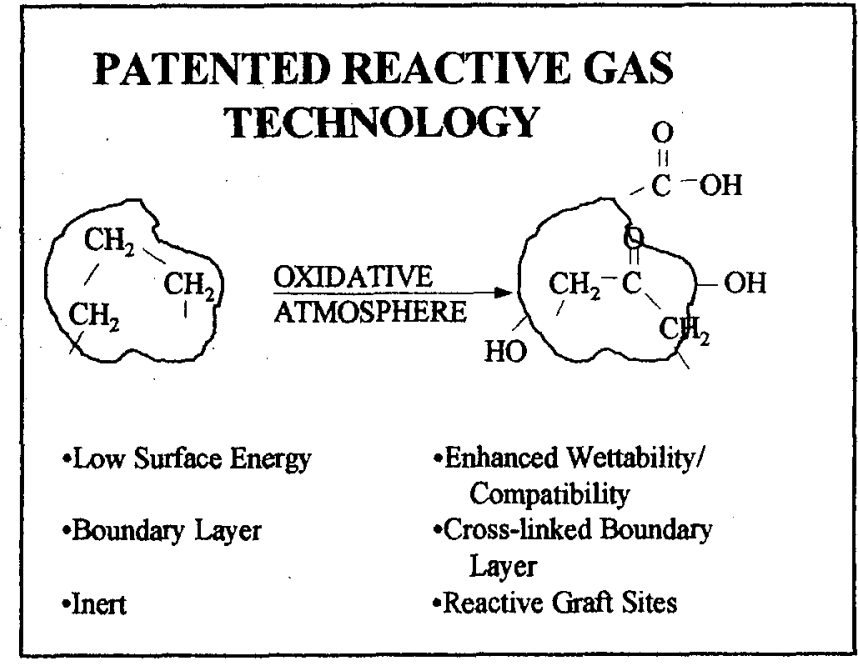




\section{Formation of New Composites}

Combination of VISTAMER ${ }^{\text {TM }}$ Rubber particles with other polymer materials results in formation of novel polymer-polymer composite materials, Figure 2 . This is because the rubber particles retain their particulate structure, and two or more domains are present. Each polymer-polymer composite material has a unique set of physical properties.

Figure 2

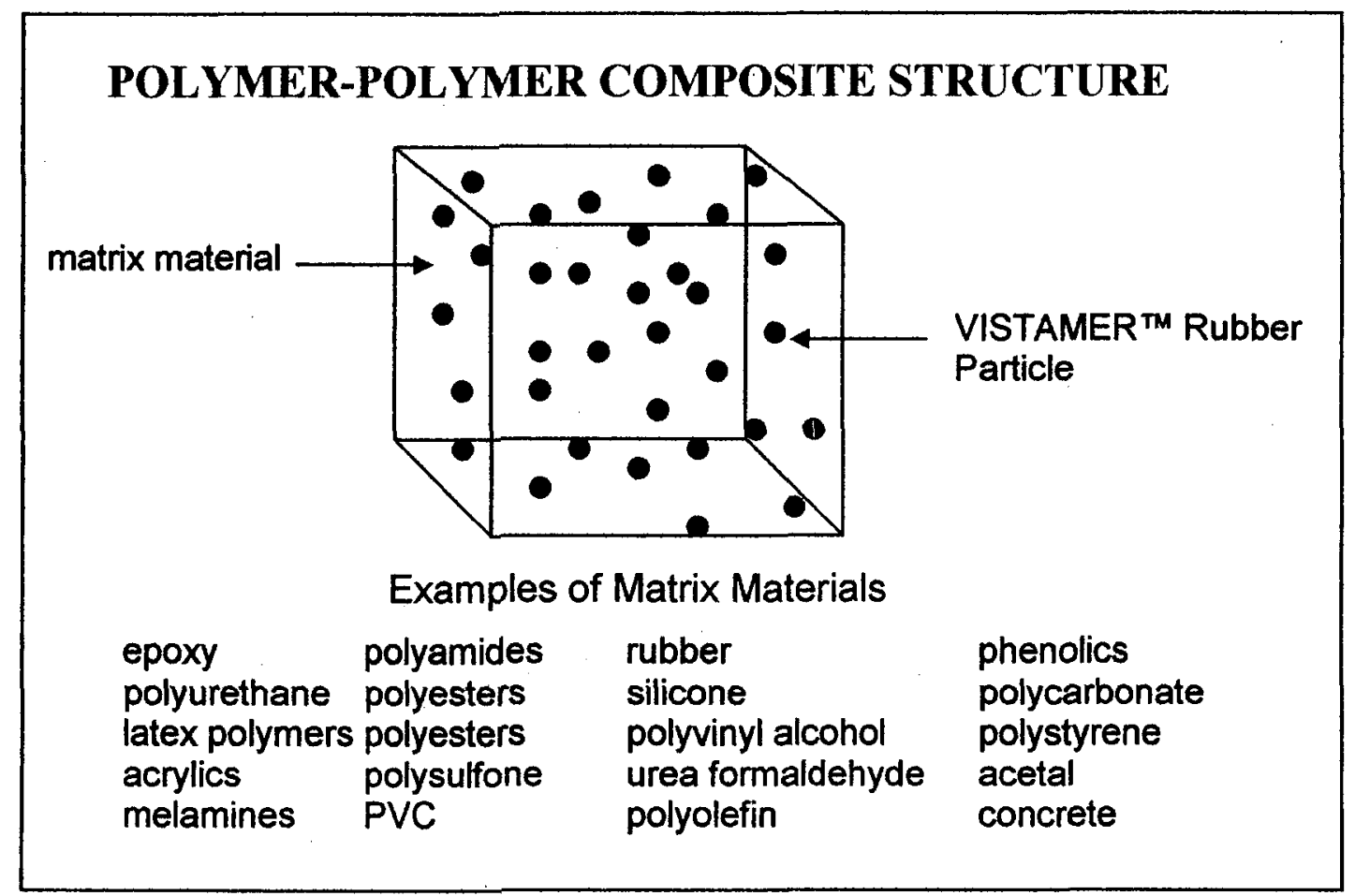

Because of the physical properties of the material can be fine tuned by changing variables such as the type/grade of matrix polymer, loading level of rubber particles, and particle size of rubber, there is great opportunity to custom design materials that have optimal properties for specific applications. (On the other hand, this large number of variables can make optimization of a formulation a somewhat daunting task.)

\section{Treatment Process}

The surface-modification process is quite simple. The rubber particles are mechanically agitated as a preblended reactive gas mix is flowed through them. Agitation is necessary to ensure uniform treatment to all particles, and to facilitate heat transfer (cooling) via jacketed rector walls as the reaction is mildly exothermic. The reaction is very rapid and nearly quantitative.

\section{TASK I Results}

Numerous process developments were made during this project. These resulted in greater throughput in given size equipment and greater quality. Examples of such process optimization included definition of optimal operating temperature, definition of 
optimal gas composition, and identification of optimal rate of gas addition. Much was also learned about controlling particle size of rubber (deagglomeration), removal of reinforcement fibers, and discharge gas filtration. In addition, much was learned concerning materials of construction that can be used in the process, which must meet requirements of chlorine compatibility and abrasion resistance.

Two engineering design studies were done to compare several variations of continuous and batch processes. It was concluded by the engineers doing the analyses that a continuous batch process is superior to a totally continuous process. In the continuous batch approach, everything is continuous except for the surface-modification step, which is done batchwise, The chemistry is so fast that a $2,000 \mathrm{lb}$ batch can be treated in approximately 3 minutes, including filling the reactor, performing treatment, and emptying the reactor. The major benefit of continuous batch processing over continuous processing is that it is easier to measure/control the amounts of rubber particles and gas addition, which results in lower capital requirements and reduced maintenance problems.

A detailed engineering design was developed for scaling up the treatment process to a 30 million $\mathrm{lb} /$ year operation.

\section{b. TASK II - Applications Development}

\section{Particularly Challenging}

The most important issue addressed by this phase of the project was whether there are substantial markets for surface-modified rubber particles. Answering this question was somewhat complicated. Surface-modified rubber particles are designed to be used in applications where nontreated rubber particles do not work well. When surface-modified rubber particles are combined with other polymers, almost all of the resulting material properties are changed somewhat. In order for a material to be amenable for a specific application (to be made into a specific end product), many physical property requirements must be met. Therefore, just because one important property is improved, for example toughness, it is equally important that all other necessary properties, for example tensile strength, also be achieved. Frequently the various physical properties can be fine tuned or even significantly changed by making subtle changes to a formulation, such as different grades of resins, different curatives, and other fillers and additives. Thus, just because all properties are not as desired in the first attempts does not mean that success cannot be achieved with some reformulation. In addition, incorporation of particulate additives in some systems is not currently done and modifications to equipment and processes are required. This sort of applications development can only be done by people that are in each market sector; only they understand the total requirements and limitations of new materials. Thus, to perform this task we had to get prospective end users (customers) to perform most of the formulation and development work. Their incentive for doing this work was the possibility of making their products with better properties and/or at lower costs. We did not have much control over exactly what they tried, and we were not told many details of their results. Furthermore, there is significant reluctance on the part of industry to adopt a new material that is not in widespread use and has a long track record. Because of that, many companies will not even waste their time looking at new materials. 


\section{TASK II Results}

The development of applications for surface treated rubber particles was a three pronged approach. It utilized technical consultants, in-house development, and to a large extent, development work by prospective end - users (customers).

\section{a. Consultants}

One important component in our approach to performing this task was to retain consultants who were experts in various fields (examples include cast polyurethane, epoxy adhesives, latex coatings). We had these experts make various formulations using treated rubber particles and then characterize the resulting physical properties. We then asked the consultants what types of applications would be most amenable to materials with the new sets of physical properties. If it made sense, we would then have the consultants develop specific starting formulations that meet industry requirements. An example is automotive adhesives. We then used these "starting formulations" to induce manufacturers to look at use of treated rubber - having proven general technical feasibility.

The types of polymer systems for which these consultant studies were performed are summarized in Table 1.

Table 1

\section{Matrix Polymers}

\begin{tabular}{|l|l|}
\hline Polyurethane & Phenolic \\
\hline Epoxies & TPU \\
\hline Acrylic latex & Natural rubber latex \\
\hline polysulfide & Nitrile rubber \\
\hline
\end{tabular}

Reports from consultant studies on some of these systems are in Appendix I.

\section{b. Presentations, Articles and Technical Literature}

Another element in our strategy for developing applications involved giving technical presentations and getting technical articles published. By presenting the concept of making new materials with treated rubber particles and supporting it with data and examples of commercial successes, many molders and formulators were stimulated to request free samples and to development work on their own. Data from the consultant studies above provided starting formulations and demonstrated technical feasibility. Potential markets, as indicated from consultant studies, provided direction on types of conferences and publications to target.

Copies of some of these papers are in Appendix II.

Copies of Technical literature on VISTAMER ${ }^{\mathrm{TM}}$ rubber developed by CPI are in Appendix III. 


\section{c. Demonstrated End-Uses}

The potential market for VISTAMER rubber particles is large and diverse. Discussed below are the major market sectors where Composite Particles, Inc. was selling VISTAMER rubber.

\section{COATINGS, ADHESIVES AND SEALANTS}

The fastest growing customer base for VISTAMER rubber, this market accounted for nearly $75 \%$ of the company's VISTAMER ${ }^{\circledR}$ Rubber particle sales. These markets can be broken down as follows:

\section{Architectural Coatings}

This product category includes paint consumed for residential, retail, and office use. Several of the world's largest paint companies are customers of CPI. VISTAMER $^{(1)}$ rubber particles are used in these applications to create texture, improve slip resistance, and provide greater abrasion resistance.

The total U.S. market for architectural coatings is 700 million gallons/year. Based on performance and cost considerations, it is estimated that the market potential for VISTAMER ${ }^{\circledR}$ particles in this product category is approximately $\$ 5$ million/yr.

\section{Industrial Floor Coatings}

This product category includes concrete floor coatings used in factories, warehouses, mechanical rooms, automotive dealerships, etc. A wide variety of coatings are required in these applications, including epoxies, acrylics, and urethanes. VISTAMER ${ }^{\circledR} \mathrm{R}$ and RW particles are added to improve toughness, crack bridging properties, and slip resistance.

An exciting new product developed by Shell Chemical Company incorporates VISTAMER $^{\circledR}$ RW particles into a thick (1/4 - 1 inch) epoxy floor coating. With VISTAMER $^{\circledR}$ RW rubber, this coating has the properties of a rubber mat, and can be used in fatigue flooring in factories, laboratories, checkout stands, animal pens, etc. The world's largest supplier of epoxy resins (Shell) has embraced VISTAMER $^{\circledR}$ rubber in this flexible epoxy floor mat application, and is promoting a formulation with $65 \%$ VISTAMER ${ }^{\circledR} \mathrm{RW}$ particles.

Current usage for epoxy resins used in floor coatings is 50 million $\mathrm{lb}$./year. The amenable market potential for VISTAMER ${ }^{\circledR}$ RW particles in trowelable and selfleveling epoxy floor coatings is estimated to be approximately $\$ 16$ million/yr.

\section{Concrete Waterproofing}

This product category includes urethanes used to waterproof parking garages (found at airports, hospitals, universities, commercial office buildings, etc.) and balconies (condominiums, hotels, resorts, etc.). In this application, VISTAMER ${ }^{\circledR}$ RW particles are used primarily as a slip resistant aggregate, replacing sand -which it outperforms. 
The total area of concrete waterproofing membranes installed in North America is approximately 75 million $\mathrm{ft}^{2}$ /year. CPI believes that virtually all of this market is amenable for use of VISTAMER ${ }^{\circledR}$ RW particles. An average usage rate of 5 $\mathrm{lb} . / 100 \mathrm{ft}^{2}$ equates to a $\$ 2$ million/yr potential market.

\section{Construction Adhesives and Sealants}

This product category includes adhesives used to seal the joint between concrete slabs, between a road surface and a bridge deck, and sealants applied to expansion joints found in numerous concrete structures. VISTAMER ${ }^{\circledR} R$ and RW particles improve the elongation, crack bridging, and tear resistance of these products. Construction adhesives and sealants consume 236 million $\mathrm{lb}$. of polyurethane resins per year. CPI estimates that about $50 \%$ of these applications could use VISTAMER $^{\circledR}$ rubber. A $20 \%$ loading level equates to a $\$ 12$ million/year potential market.

\section{POLYURETHANE APPLICATIONS}

\section{Cast Urethanes}

VISTAMER $^{\circledR} \mathrm{R}$ and RW particles are used in cast polyurethanes to increase traction or grip, and to reduce raw material costs. CPI had a number of customers who used the product on a regular basis to manufacture drive rolls and flexible belts. Alshin Tire, Inc. used VISTAMER ${ }^{\circledR}$ rubber to improve the wet traction of their microcellular polyurethane wheelchair tires. Other cast polyurethane applications such as forklift tires, rollerblade wheels, and industrial rollers also benefit from the use of VISTAMER ${ }^{\circledR}$ rubber.

Current usage of cast polyurethanes in North America is approximately 133 million $\mathrm{lb}$./year. CPI estimates that about $40 \%$ of this market is amenable to use of VISTAMER ${ }^{\circledR}$ particles. A $15 \%$ loading level equates to a $\$ 23$ million/year potential for VISTAMER ${ }^{\circledR}$ rubber and polyethylene particles.

\section{Polyurethane Foam}

Flexible polyurethane foam is widely used in upholstery, automotive seating, carpet underpads (underlay), and dunnage (packing for shipping). Approximately 4 billion $\mathrm{lb}$. of polyurethane foam is produced annually in North America.

Incorporation of VISTAMER ${ }^{\otimes} \mathrm{R}$ and RW particles in polyurethane foam results in improvements in a number of physical properties. One manufacturer has been developing a carpet underpad using VISTAMER ${ }^{\circledast}$ rubber for the past 3 years, and is on the verge of commercializing this product on a large scale. The customer anticipates the purchase of more than 1 million $\mathrm{lb}$. of VISTAMER ${ }^{\circledR} \mathrm{RW}$ in the first year, with annual usage growing to approximately 15 million $\mathrm{lb}$. ( $\$ 7$ million) in $4-5$ years. If this customer is successful in implementing an aggressive additional marketing strategy, they project using as much as 50 million $\mathrm{lb}$./yr in 2 - 3 years. This same company is also commercializing a shoe innersole pad based on VISTAMER ${ }^{\circledR}$ RW particles. 


\section{NITRILE RUBBER GOODS}

Nitrile rubber is used to make a variety of o-rings, seals, gaskets, and footwear soling. VISTAMER ${ }^{\circledR} \mathrm{R}$ and RW particles reduce raw material costs while retaining most important physical properties.

Approximately 169 million $\mathrm{lb}$./year of nitrile rubber is produced in North America, and approximately $10 \%$ of this is amenable to VISTAMER ${ }^{\circledR}$ rubber particles. A $20 \%$ loading level equates to a $\$ 2$ million/year potential market.

\section{RIGID PVC GOODS}

Rigid polyvinyl chloride (PVC) is used to make house siding, pipes, house window frames, and tubing. Incorporation of VISTAMER ${ }^{\circledR} R$ and RW particles in PVC improves properties such as toughness and impact resistance.

Approximately 8 billion $\mathrm{lb}$./year of rigid PVC is purchased in North America, and perhaps $10 \%$ of the applications are amenable to VISTAMER ${ }^{\circledR} \mathrm{R}$ and $\mathrm{RW}$ particles. A $5 \%$ loading level equates to a $\$ 40$ million/year potential market.

\section{d. Market Summary}

The estimated market potential for CPI's surface-modified rubber particles in North America for demonstrated applications is summarized in Table 2. These estimates are based on applications that have been commercialized by customers or are in various stages of development.

It is expected that additional markets for VISTAMER ${ }^{\circledR}$ products will be identified in the long run, and that these markets will be significantly larger than these initially-developed applications. The ultimate market for surface-modified rubber particles in the U.S. is projected to be approximately 1 billion lb/year, with a market value of approximately $\mathbf{\$ 6 5 0}$ million/year. The basis of this estimate is the use of VISTAMER ${ }^{\text {TM }}$ Rubber composites in place of other materials currently in use, and the incorporation of VISTAMER rubber in future applications. This will be supported by more people learning of the existence of this material in the future, and as it obtains further credibility as it passes the test of time. 


\section{Table 2}

\section{SUMMARY OF DEMONSTRATED MARKETS FOR VISTAMER ${ }^{\circledast}$ RUBBER PARTICLES}

\section{APPLICATIONS}

\section{Cast PU}

- wheels, tires, rollers

- shot blast medium

- shoe soles

PU foam

- carpet underlay

- footwear innersoles

- roof tiles

PU non-slip coatings

Adhesives \& sealants

Epoxy non-slip coatings

Epoxy floor coatings

- trowelable

- self-leveling

Novalac coatings

Acrylic latex paint

Rigid PVC

\section{BENEFITS}

ESTIMATED MARKET

(\$ millions)

wet traction, cost reduction

better adhesion

$\$ 23$

wet traction, cost reduction

recycle content, properties

recycle content, properties

compatibilizes asphalt/polyol

better performance

better flexibility, greater adhesion

greater coefficient of friction

improved flexibility

greater impact resistance

greater flexibility

slip-resistance, aesthetics, toughness

5

impact resistance

Total 


\section{TASK III - Economics, Energy and Environmental Impact}

\section{Economics}

The economics for this technology are remarkably favorable. The variable costs are low (Table 3), capital requirements are very modest (Table 4), and the value of the treated rubber is quite high.

Table 3

\begin{tabular}{|c|c|c|}
\hline \multirow[t]{3}{*}{$(\$ / 1 b)$} & \multicolumn{2}{|c|}{$\begin{array}{l}\text { VARIABLE COSTS } \\
\text { for } 60 \text { mesh RW product }\end{array}$} \\
\hline & Actual & Larger Scale (Est.) \\
\hline & 0.244 & 0.220 \\
\hline chlorine & 0.006 & 0.004 \\
\hline caustic & 0.001 & 0.001 \\
\hline packaging (bags, pallets) & 0.013 & 0.012 \\
\hline utilities & 0.010 & 0.010 \\
\hline labor (@\$25/hr) & 0.023 & 0.008 \\
\hline total & 0.297 & 0.255 \\
\hline
\end{tabular}

Table 4

\section{Capital Costs}

\begin{tabular}{|l|c|}
\hline $\begin{array}{l}\text { Larger scale system (approximately 30 million } \\
\text { lb/year, @ } 3 \text { shifts/day) includes, engineering, } \\
\text { ancillaries, and } \\
\text { installation. }\end{array}$ & $\$ 1,200,000$ \\
\hline $\begin{array}{l}\text { Amortization of capital (\$1.2 million) over } 3 \\
\text { years of production (90 million lb), assuming full } \\
\text { capacity }\end{array}$ & $\$ 0.013 / \mathrm{lb}$ \\
\hline
\end{tabular}

\section{Prices for various types of polymers}

There are two reasons that molders and formulators specify surface-modified rubber particles; to reduce costs and or to improve the properties and performance of end products made. It is important that VISTAMER $B$ Rubber is less expensive than most of the polymer systems to which they are added. Ranges of pricing for some of the amenable polymer systems are listed in Table 5. For comparison, VISTAMER Rubber was priced in the range of $\$ 0.50$ to $\$ 1.49 / \mathrm{lb}$. 
Table 5

Prices for Matrix Polymers

\begin{tabular}{|l|l|l|l|l|}
\hline Polyurethane & $\$ 3.50-5.00 / \mathrm{lb}$ & & Acrylic latex & $\$ 0.80-1.25 / \mathrm{lb}$ \\
\hline Epoxy & $\$ 0.75-\$ 1.50 / \mathrm{lb}$ & & Phenolic & $\$ 0.70-1.00 / \mathrm{lb}$ \\
\hline TPU & $\$ 1.25-\$ 1.75 / \mathrm{lb}$ & & Polysulfide & $\$ 1.75-2.15 / \mathrm{lb}$ \\
\hline Nitrile rubber & $\$ 0.90-\$ 1.60 / \mathrm{b}$ & & Nylon & $\$ 1.75-2.00 / \mathrm{lb}$ \\
\hline
\end{tabular}

\section{Energy}

This technology represents the highest energy value for scrap rubber. The high energy value arises from the fact that surface-modified scrap rubber particles are used in place of virgin polymers in various applications, and because the energy requirement to make surface-modified rubber particles are modest. It is estimated that it takes approximately $30,000-100,000$ BTUs to manufacture a pound of virgin polymer. It only requires approximately 2,000 BTU to make $1 \mathrm{lb}$ of surface-modified rubber particles. This includes size reduction, manufacturing the reagents, and performing surface modification. Thus the energy saved by using surface-modified rubber particles in place of virgin polymers is approximately $28,000-98,000 \mathrm{BTU} / \mathrm{lb}$.

Burning scrap tires for energy only recovers about $14,000 \mathrm{BTU} / \mathrm{lb}$. This is nearly identical to the energy content of coal. But coal costs only $\$ 0.03-0.04 / \mathrm{lb}$.

It is projected that widespread use of this surface-modification technology can save the nation in excess of 0.4 Quad BTU/year.

\section{Environmentally Friendly and Non-Polluting}

This technology is non-polluting. Essentially all of the reactive gas reacts with the rubber particles to form stable products. The trace amounts of reactive gas and gas byproducts are easily scrubbed (neutralized) so that there are no toxic emissions. The processes of grinding scrap tire rubber and manufacturing chlorine are environmentally benign. In addition, toxicological testing has indicated that the treated rubber particles are non-toxic and safe in the environment.

Thus, in comparison to not reusing scrap tires, with its scrap tire fires and land, air and water pollution, and problems with disease-laden mosquito vectors, practicing this technology is beneficial to the environment.

\section{TASK IV Technology Transfer}

Technology transfer in this project consisted of presenting progress reports to the U. S. Department of Energy on a periodic basis, presenting numerous technical papers at various technical conferences, and giving technical presentations at numerous prospective end users. 


\section{CONCLUSIONS AND RECOMMENDATIONS}

This is a great technology. It facilitates manufacturers to make end products with superior properties, it enables end products to be made with lower raw material costs, it will save the nation a considerable amount of energy, and it will help reduce the environmental problems associated with scrap tires.

Ideally, the surface modification process should be done by tire grinders as an incremental added process in their operations. In this way, the costs for treated rubber can be minimized because no additional shipping, packaging, or overhead are required. By being able to offer treated rubber at the lowest possible price, the amenable market will be maximized. Ideally surface-modified rubber will be promoted by a company that has high visibility and credibility in the polymer market. Furthermore, the technology should be sponsored by a company that has sufficient resources to continue promotion and development into new applications, and to have staying power to allow the time required for commercial acceptance of new technology.

Composite Particles, Inc. has several patents, foreign and domestic, on this technology. As Composite Particles was being wound down, the patents were sold to Dr. Bernard Bauman. As the inventor of the technology and founder of Composite Particles, Dr. Bauman is personally committed to continue seeking licensees for the technology. Several past customers of VISTAMER rubber continue to ask about when it will be available again. Dr. Bauman is hopeful that this technology will be licensed to at least one firm by the end of 2002 . 